\title{
Tratamiento supresivo con tiroxina para nódulos tiroideos. ¿Cuál es la evidencia?
}

Thyroxine suppressive therapy in patients with nodular thyroid disease.

Gharib H, Mazzaferri E. Ann Intern Med 1998; 128:386-394

\section{Objetivo}

Determinar el sustento bibliográfico del tratamiento supresivo con tiroxina (TST) en la enfermedad nodular benigna tiroidea.

\section{Fuente y Selección de datos}

Búsqueda en Medline de estudios randomizados y no randomizados en inglés publicados entre 1986 y 1996; y artículos de archivos personales de los autores. Los estudios incluyeron:

1. Datos de Punción aspiración (PA) de los nódulos.

2. Supresión de TSH mediante prueba de TRH-TSH o determinación de TSH mediante ensayos sensibles.

3. Disminución a un $50 \%$ en tamaño o volumen del nódulo, por palpación o, más recientemente, por ecografías.

\section{Extracción de datos y Resultados principales}

Se analizaron los siguientes aspectos del TST:

1. Identificar nódulos benignos que responden a TST.

No hay evidencia que lo sustente. Hasta 15\% de los cánceres disminuyen de tamaño con TST. La precisión diagnóstica de la PA supera ampliamente al TST como herramienta diagnóstica.

2. Disminuir el tamaño de nódulos citológicamente benignos para minimizar el riesgo de falsos positivos en la PA.
Evidencia grado III *. Los falsos negativos son menos del $2 \%$ y no hay justificación para TST.

3. Disminuir el tamaño de nódulos por razones cosméticas o para evitar cirugía. Evidencia grado I (con recomendacion tipo E)* ${ }^{\star}$. En los estudios randomizados y controlados por placebo la disminución del tamaño no difirió entre los grupos. Aunque todos tuvieron disminución significativa con respecto a sus tamaños basales. Los nódulos decrecen espontáneamente con el tiempo.

4. Disminuir el mayor crecimiento de nódulos preexistentes.

No hay estudios que evalúen esta situación.

5. Prevenir recurrencia de nódulos postquirúrgicos.

Evidencia grado I (recomendación E)* . Ningún estudio controlado mostró diferencias entre pacientes que recibieron y no recibieron TST. 6. Evaluar los efectos adversos del tratamiento.

Aumenta el riesgo de osteoporosis y podría aumentar el riesgo de fibrilación auricular (Evidencia grado III)*.

\section{Conclusiones}

No hay evidencia que sustente el TST. La evidencia existente recomienda no utilizarlo y los riesgos potenciales son considerables. Con el perfeccionamiento de la PA, no quedan indicaciones para el uso de TST.

\section{COMENTARIO}

Cuando en los años 20 les preguntaron a los renombrados escaladores Irvine y Mallory por qué se empecinaban en escalar el Monte Everest, su respuesta fue "Porque está ahí". Ese era motivo suficiente para continuar en su empeño; el cual, como se sabe, les costó la vida. Cuando estamos frente a un paciente con un bocio nodular asintomático, y los estudios habituales no indican un riesgo inminente, se nos plantea un interrogante similar: ¿Por qué deberíamos tratarlo en vez de esperar y vigilar su evolución? Y la respuesta que recibimos por parte de muchos colegas endocrinólogos, es la misma: "Porque está ahi”. Los autores del artículo, reconocidos expertos en el tema, se plantean la misma pregunta, sin encontrar evidencia bibliográfica que sustente el TST .

En sus conclusiones recomiendan:

1. Efectuar PA en todo nódulo palpable, en todo nódulo $\geq 1.5 \mathrm{~cm}$ de diámetro por ecografía y/o cuando presenta signos ecográficos de sospecha ("halo", “nódulo dominante").
2. Vigilar a los no biopsiados y a los que resultaron negativos mediante ecografías seriadas "frecuentes" (no especifican el lapso). Enfatizan su preferencia por una conducta expectante en vez de terapia supresora para los nódulos tiroideos. En un editorial acompañante, el Dr. E. C. Ridgway coincide en general con los autores, aunque acepta la posibilidad de terapia con tiroxina cuando luego de un año de vigilancia el nódulo aumentó de tamaño. Para ello propone un algoritmo, que sin ser perfecto, puede ser una guía útil.

A los signos de sospecha ecográfica mencionados por los autores, sugiero agregar el signo muy valioso de "vascularización penetrante" en el nódulo (1), el cual en nuestra experiencia, tiene un alto valor predictor de carcinoma tiroideo. Aún admitiendo que un nódulo pueda disminuir en tamaño con hormonoterapia, ¿existe alguna prueba qué con ello se disminuye su potencial de proliferación maligna? Evitemos tratar algo sólo "porque está ahí"...

*Ver Glosario $\mathrm{N}^{\circ} 2$

\section{Dr. Martín Roubicek}

Servicio de Endocrinología. Hospital Privado de Comunidad de Mar del Plata.

\section{Referencias}

1. Feldman M, Rodriguez M J, Roubicek M. Sensibilidad y especificidad de la

ecografía en el diagnóstico diferencial de nódulos tiroides. II Congreso de la FASEN, Tucumán 1996, Argentina. 